\title{
PROJETO VIÁRIO, ESPECULAÇÃO DE TERRAS E SUPRESSÃO DE ESPAÇOS PÚBLICOS: ESTUDO SOBRE A FAIXA DE DOMÍNIO DA AV. PREFEITO OMAR O'GRADY - NATAL/RN
}

\author{
Camila Furukava ${ }^{1}$
}

Simara Vale ${ }^{2}$

Maria Dulce P. Bentes Sobrinha ${ }^{3}$

\begin{abstract}
RESUMO
Esse artigo apresenta uma reflexão sobre projetos viários e apropriação de áreas públicas, tendo em vista a supressão de áreas necessárias para configuração da faixa de domínio identificada em uma fração do projeto de prolongamento da Av. Prudente de Morais, em Natal/RN. Nesse caso, verificouse a eliminação dos espaços para acostamento, ciclovias, entre outros. A partir dessa questão, o presente artigo busca evidenciar o processo de supressão dos espaços públicos após a implantação da Via, através da identificação das sucessivas transferências de dominialidade. Os procedimentos adotados foram: levantamento dos projetos viário e do loteamento da área em estudo, trabalho de campo com registro fotográfico e identificação do uso do solo, busca de dados de registro dos imóveis em Cartório, superposição do mapa original com a foto aérea da área de estudo, além da verificação dos percentuais de áreas públicas subtraídas com a projeção do loteamento. Conclui discutindo efeitos da supressão de parte da faixa de domínio, que resultou em um projeto viário destituído de componentes da Política Nacional de Mobilidade Urbana. Reflete sobre entraves que se impõem ao controle social, face à ausência de transparência sobre as terras públicas e suas destinações.
\end{abstract}

PALAVRAS CHAVE: Projetos Viários. Espaços Públicos. Política Fundiária.

\footnotetext{
${ }^{1}$ Arquiteta Urbanista (UFRN), Tecnóloga em Produção Civil (IFRN). Mestre em Arquitetura e Urbanismo (UFRN). Doutoranda do Programa de Pós Graduação em Arquitetura e Urbanismo da UFRN. camilafurukava@gmail.com

${ }^{2}$ Graduanda do Curso de Arquitetura e Urbanismo (UFRN).simara_valle@hotmail.com ${ }^{3}$ Arquiteta Urbanista (UFRN), Professora Doutora do Depto. de Arquitetura e do Programa de Pós Graduação em Arquitetura e Urbanismo (UFRN). dubentes@gmail.com
} 


\title{
ROAD DESIGN, LAND DISPUTES AND SUPPRESSION OF PUBLIC SPACES: STUDY OF THE RANGE OF THE FIELD OF AV MAYOR OMAR O'GRADY - NATAL / RN
}

\begin{abstract}
This article presents a reflection on road projects and appropriation of public areas, with a view to abolition of necessary areas for configuring and highway identified in a fraction of Prudente de Morais Avenue extension project, in Natal / RN. In this case, there is the elimination of shoulder spaces, bike paths, among others. From this question, this article seeks to show the process of suppression of public spaces after the implementation of the Way, by identifying the successive transfers of dominion. The procedures adopted have been: survey of road projects and the area of allotment been studied, field work with photographic record and identification of land use, real estate search log data on subtracted with the projection of the allotment. It has been conclude discussing effects of suppression of the part of right way, which has been resulted in a road project devoid of components of the National Urban Mobility Policy. It has reflected on barriers that impose social control, in the absence of transparency on public lands and their destinations.
\end{abstract}

KEYWORDS: Road Projects. Common Public Lands. Landpolicy.

\section{PROYECTO DE RUTAS, DISPUTAS POR LA TIERRA Y LA SUPRESIÓN DE LOS ESPACIOS PÚBLICOS: UN ESTUDIO DE LA ZONA DE SEGURIDAD DE LA AV, ALCALDE OMAR O'GRADY - NATAL / RN.}

\section{RESUMEN}

Este artículo presenta una reflexión sobre los proyectos de carreteras y la apropiación de los espacios públicos, lo que resulta en la supresión de la zona de seguridad. Este problema fue identificado en una fracción del proyecto de ampliación de la avenida Prudente de Morais, en Natal / RN - la Av. Alcaide Omar O' Grayd. En este caso, no identifica el área de seguridad, espacios de circulación de bicicletas, paseos adecuados y otros componentes de la movilidad sostenible. Teniendo en cuenta este problema, este artículo tiene como objetivo mostrar el proceso de supresión de espacios públicos con la construcción de la avenida, mediante la identificación de las sucesivas transferencias de propiedad. Los procedimientos adoptados fueron: análisis del proyecto de expansión de la avenida Prudente de Morais; trabajo de campo con registro fotográfico y la identificación del uso de la tierra; investigación sobre los registros de la propiedad de la tierra en la Notaría; superposición del mapa 
Revista Nacional de

Gerenciamento de Cidades

original de zona con la foto aérea de la zona de estudio y análisis del porcentaje de zonas comunes eliminadas con la proyección de la asignación. Se concluye con una discusión de los efectos de la eliminación de parte de la zona de seguridad, que se tradujo en un proyecto de carretera sin los componentes de la Política Nacional de Movilidad Urbana. Refleja sobre las barreras que imponen el control social, a falta de transparencia en las tierras públicas y sus destinos.

PALABRAS CLAVE: Proyectos de Carreteras, Espacios Públicos, Política de Tierras.

\section{INTRODUÇÃO}

Os projetos viários, como componentes da infraestrutura urbana local e metropolitana, exercem forte papel nas transformações dos espaços urbanos e territoriais, atuando junto aos processos de valorização do solo e no incremento da disputa por terras na cidade e/ou região. $O$ interesse que a terra exerce enquanto "terra-localização", se expressa pela sua valorização, que é reforçada pela facilidade de acesso às demais regiões da cidade e pelo trabalho socialmente dispendido em sua produção (VILLAÇA, 2007). As terras lindeiras aos projetos viários estruturantes se incluem entre aquelas de grande disputa pelas empresas privadas, em especial do setor imobiliário, que buscam, entre outros, ampliar o estoque de terras e promover a abertura de novas centralidades.

Para Ana Fani Carlos, na contemporaneidade, o espaço urbano é, como força produtiva e mercadoria, necessário para o processo de reprodução do capital. Neste sentido, a produção do espaço torna-se, ao mesmo tempo, um momento constitutivo da vida humana, a efetivação do processo de valorização, portanto condição de realização do capital e da concretização do Estado como produtor de um território de dominação (CARLOS, 2015 p.44-45). Assim, na ausência de uma política fundiária adequada, voltada para a justa distribuição dos benefícios da urbanização, observa-se o incremento dos processos especulativos da terra com prejuízo sobre a salvaguarda do interesse público e da efetivação do Direito à Cidade. 
Revista Nacional de

Gerenciamento de Cidades

Essa questão foi observada na implementação do projeto de expansão e prolongamento viário da Av. Prudente de Morais, denominada Av. Prefeito Omar O'Grady, em Natal/RN. Trata-se de um eixo estruturante, que conecta as Zonas Leste e Sul da cidade e atravessa Áreas Especiais de Interesse Social (AEIS) e as Zonas de Proteção Ambiental do Parque da Cidade (ZPA 1) e do Pitimbu (ZPA 3), ambas com características de campo dunar e repositoras do aquífero da cidade (NATAL, 2007). A presença de cercas e anúncios imobiliários nas áreas lindeiras à referida Via nos levaram a questionar o espaço destinado à faixa de domínio, tendo em vista que não havia mais de três metros entre a Via e o limite da cerca.

A definição de espaços livres no entorno das vias é uma discussão antiga e está referenciada pela Lei nacional $\mathrm{n}^{\circ} 6766 / 79$, que dispõe sobre o parcelamento do uso do solo e pela Lei oㅡ 6204/91 que dispõe sobre licença prévia para edificações de imóveis ou cercas às margens de rodovias estaduais, no Estado do Rio Grande do Norte.

As faixas de domínio são relevantes para assegurar a ampliação dos sistemas de infraestrutura, espaços de acostamento, abrigos e baias de paradas de ônibus, arborização dos passeios e áreas voltadas à equidade no uso do espaço pelos diversos modais e a segurança dos usuários, diante das diferentes velocidades e características técnicas de cada meio de transporte. Neste caso, cabe ao poder público realizar as desapropriações de imóveis nestas faixas, em especial em áreas de expansão urbana que se encontram sem ocupações consolidadas, transformando as áreas lindeiras em espaços públicos de uso coletivo.

Considerando a lei estadual ํo 6204 , temos que "a faixa de domínio é definida como a área de terra limitada pela distância mínima de 20 (vinte) metros de cada lado da rodovia medidos do eixo da pista de rolamento", e que "as edificações ficam sujeitas a um recuo de 15 (quinze metros) dos limites externos da faixa de domínio". Nesse sentido, indagamos de que maneira parte das áreas lindeiras do prolongamento viário da Av. Prudente de Morais haviam sido suprimidas e estavam sendo apropriadas? Nossa hipótese inicial foi que as terras lindeiras destinadas à 
Revista Nacional de

Gerenciamento de Cidades

faixa de domínio do prolongamento da Av. Prudente de Morais haviam sido privatizadas.

Essa questão norteou os estudos cujos resultados apresentamos no presente artigo. O objetivo é evidenciar o processo de supressão dos espaços públicos após a implantação da Via, através da identificação das sucessivas transferências de dominialidades.

Para tanto, realizamos o estudo de dominialidade das frações lindeiras à Avenida Omar O'Grady, etapas II e III do conjunto habitacional Cidade Satélite, no Bairro Pitimbu, entre a Avenida Xavantes e a Av. Rio Tamanduateí. Verificamos o mapa original do conjunto Cidade Satélite com identificação das áreas verdes e de uma faixa remanescente, em áreas lindeiras da Via, previamente projetadas em 1978.

É relevante destacar que mesmo tendo sido planejada em 1978, as obras do prolongamento, nesse trecho, só foram executadas a partir de 2007 e que tais áreas lindeiras não apresentam nenhum elemento construído até o atual momento (2015). Esse fato remete a um processo de transferência de dominialidade de propriedades e não em um processo de desapropriação de áreas adensadas para compor a faixa de domínio. Contudo, por meio do trabalho de campo identificamos a existência de um empreendimento imobiliário projetado para a área que identificamos como sendo de domínio público. A partir dessa constatação buscamos conhecer os dados do empreendimento através da mídia, órgãos públicos e cartórios, percorrendo várias fontes que resultaram em informações particionadas, mas que sobrepostas possibilitaram identificar apropriações, aferir dominialidades e verificar o processo de privatização.

Concluímos discutindo efeitos da supressão de parte da faixa de domínio e seus efeitos sobre o projeto viário e relações com a Política Nacional de Mobilidade Urbana. Refletimos sobre entraves que se impõem ao controle social, face à ausência de transparência sobre as terras públicas e suas destinações. 


\section{PROJETOS VIÁRIOS E ÁREAS LINDEIRAS: ENTRE AS FUNÇÕES PÚBLICAS E A REALIZAÇÃO DO MERCADO}

As rodovias são elementos estruturantes e conectores na e das cidades, concentrando grande fluxo de veículos e constituindo-se em espaços livres que percorrem longas extensões com diferentes características socioculturais, econômicas e morfológicas dentro das cidade. Com tal relevância, essas vias requerem constantemente intervenções, tais como as ampliações do próprio sistema e a inclusão e divisão dos espaços para diferentes modais de transporte (ciclovia, veículos leves sobre trilho, calçadas). Nesse contexto, as faixas de domínio dos eixos rodoviários constituem espaços fundamentais para a qualificação dos projetos viários nas cidades, em especial em áreas de expansão urbana.

Entretanto, uma vez que a escala de produção da cidade foi voltada a implantação do sistema viário para o automóvel particular, observa-se uma tendência à concentração e ao isolamento dos espaços públicos em praças e em áreas ambientais, assim como a privatização de grande parcela dos espaços coletivos em condomínios fechados e shoppings. Para Jan Gehl (2013), essa tendência automobilística, articulada ao ideário modernista do início do século, promoveu um isolamento das pessoas, mesmo com o crescente adensamento populacional. Isto tenciona a redução da identificação dos espaços públicos da rua, calçadas e faixas de domínio como espaços de convívio e conectores ambientais, restringindo-os a meros espaços de passagem.

A percepção do sistema viário como espaços de passagem favorece a privatização dos espaços públicos, seja por meio da prática formal de mudança na dominialidade e concessão de uso ou pela ocupação informal de comércios e habitações, limitando a área para futuras intervenções no sistema. Destaca-se ainda que a mudança de dominialidade das áreas lindeiras das vias que compõem as faixas de domínio são de responsabilidade do Poder Público Estadual/Federal, durante o licenciamento e aprovação do projeto. Por sua vez, o Poder Público, após 
Revista Nacional de

Gerenciamento de Cidades

a transferência de dominialidade, pode conceder uso e ocupação do solo para outros fins, mantendo pública a propriedade do terreno.

Em 1973 o Departamento Nacional de Estradas e Rodagem - DER, fixou as características técnicas dos projetos das estradas federais e dos planos regionais, por meio da Norma para o Projeto das estradas de Rodagem - Portarias n¹9/49 e $n^{\circ} 348 / 50$, retificados em 1973. Essa norma define que tais projetos devem prever a arborização da faixa de domínio, com objetivo de conter erosões, funcionar de sinalização viva e se enquadrar nos aspectos paisagísticos locais. Estabeleceu ainda, faixas de domínio variáveis de 30 a $80 \mathrm{~m}$ em zonas rurais e urbanas, de acordo com as características topográficas e indicou que, em trechos urbanos de elevado valor de desapropriação, a largura da faixa de domínio pode ser reduzida variando entre 20 e 40m (BRASIL, 1973).

Em seguida, observou-se a aprovação de legislações que versam sobre as faixas de domínio, como a Lei 6.766/79, que dispõe sobre o parcelamento do solo e a Lei $n^{\circ}$ 10.932/2004, que alterou a lei 6766, mas que confirmou as faixas de domínio público das rodovias e ferrovias, incluindo uma reserva de $15 \mathrm{~m}$ não edificável nas áreas lindeiras a via. No estado do Rio Grande do Norte, conforme mencionado anteriormente, a Lei 6204/1991 instituiu que a faixa de domínio é limitada pela distância mínima de $20 \mathrm{~m}$ de cada lado da rodovia, medidos do eixo da pista de rolamento e que as edificações ficam sujeitas a um recuo de $15 \mathrm{~m}$ dos limites externos da faixa de domínio, salvaguarda as edificações existentes antes do estabelecimento da lei (RIO GRANDE DO NORTE, 1991).

Atualmente a Lei 12.587/2012, que versa sobre a Política Nacional de Mobilidade Urbana - PNMU, com base na Constituição Federal de 1988 e no Estatuto da Cidade (2001), reafirma o cumprimento da função social da propriedade e os princípios do Direito à Cidade. Embora não trate especificamente das faixas de domínios, através dos seus princípios, diretrizes e objetivos, a PMNU amplia a discussão da mobilidade reforçando a promoção da acessibilidade universal e a equidade no uso do espaço público de circulação, vias e logradouros, a partir de 
Revista Nacional de

Gerenciamento de Cidades

planos e projetos de mobilidade urbana (BRASIL, 2012). Destaca-se que não é objetivo dessa lei tratar as faixas de domínio, mantendo com isto, o estabelecido nas demais legislações apresentadas. Contudo, reforça-se que as faixas de domínio são fundamentais para a concretização dos objetivos e das diretrizes desta Política.

Entretanto, sob a marcante lógica do mercado, a omissão do Poder Público em formalizar, registrar e publicizar as faixas de domínio das vias como propriedades públicas, além da frágil percepção social dessas áreas como de uso coletivo facilita os processos de especulação imobiliária, reduzindo consideravelmente os espaços públicos e a equidade na distribuição destes benefícios na cidade.

Diante da redução dos espaços públicos de convívio destinados às faixas de domínio das vias, observa-se que a abertura e a ampliação de eixos viários acontecem muitas vezes em contexto de contradições com os princípios da Política Nacional de Mobilidade. Essas questões são vistas a seguir, através do estudo de caso referente ao prolongamento da Avenida Prudente de Morais, em Natal/RN.

\section{AVENIDA PREFEITO OMAR O'GRADY - NATAL/RN: O QUE ACONTECEU COM A FAIXA DE DOMÍNIO?}

Essa foi a pergunta que se fez diante da obra de ampliação da Av. Prudente de Morais, denominada Avenida Prefeito Omar O'Grady, em Natal/RN, cuja faixa de domínio possui em torno de 3 metros de passeio público, desrespeitando os $15 \mathrm{~m}$ previstos na Lei 6766/79 e na Norma para o Projeto das estradas de Rodagem/1973. Também não considera os $20 \mathrm{~m}$ exigidos em cada lado da via, a contar do eixo da pista de rolamento, mais os $15 \mathrm{~m}$ previstos após o limite da faixa de domínio, conforme definido na Lei estadual 6204/91.

O prolongamento da Avenida Prudente de Morais é um projeto da década de 1970 contemplado no desenho urbano do conjunto Cidade Satélite, no Bairro do Pitimbu, Zona Sul de Natal. Situado no limite entre os municípios de Natal e 
$\mathrm{GC}$

Revista Nacional de

Gerenciamento de Cidades

Parnamirim, esse bairro tem localização estratégica na atualidade, constituindo-se em um dos eixos de crescimento da cidade (figura 1).

O projeto do Conjunto Habitacional Cidade Satélite de autoria do arquiteto pernambucano Acácio Borsoi foi inaugurado em 1983, e tem grande parte do parcelamento do solo preservado até os dias atuais. O conjunto foi estruturado para que seus usuários pudessem contar com amplos espaços públicos concentrados em dois grandes eixos centrais e distribuídos em largas regiões de praças. Os eixos dividem o conjunto em quatro frações, que estruturam as três etapas de sua implantação.

As duas grandes áreas livres situadas nesses eixos, com exceção das áreas verdes, foram concebidas para recepcionar projetos viários capazes de conectar o município à BR101. Atualmente o Eixo 1 (indicado na figura 1) vem sendo ocupado por condomínios fechados, impossibilitando a inserção de vias conectoras e o Eixo 2 (indicado em amarelo na figura 1) mantém a proposta original recebendo uma etapa do projeto viário de prolongamento da Av. Prudente de Morais.

\section{Figura 1.Localização do Bairro Pitimbu e das Zonas de Proteção Ambiental 1} (San Vale) e 3 (Pitimbu)

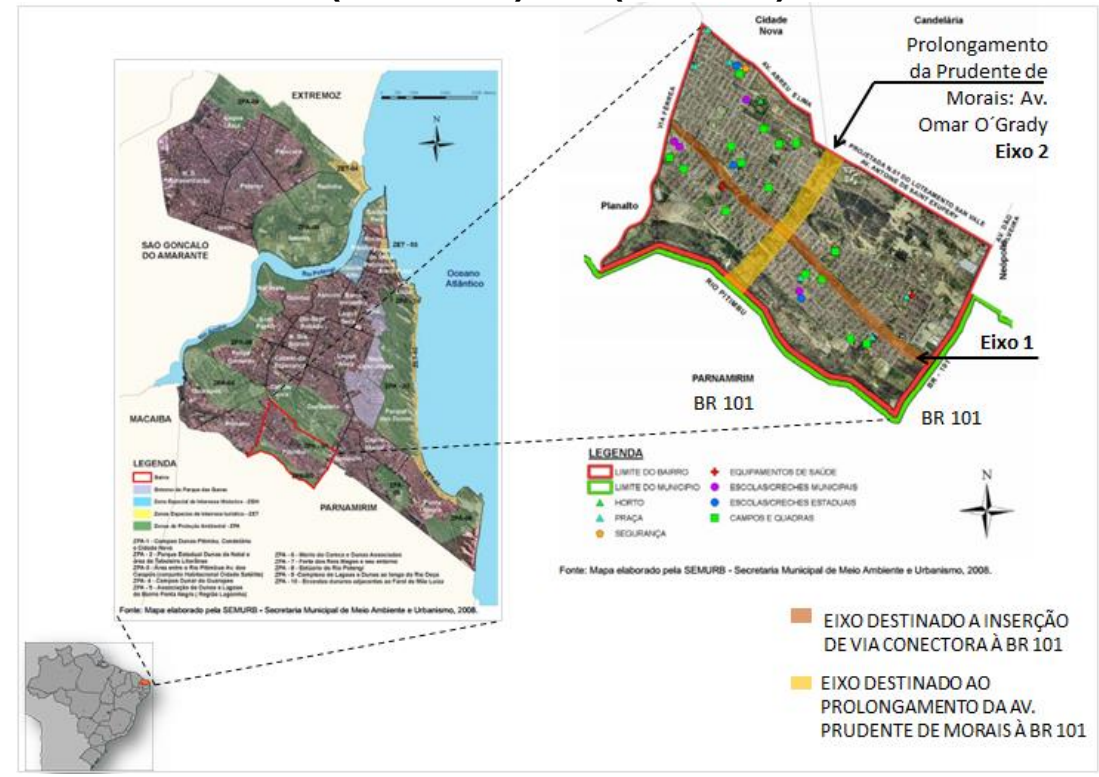

Fonte: Hora, 2008. Alterado pelos autores 
GC

Revista Nacional de

Gerenciamento de Cidades

Cabe destacar que a Av. Omar O'Grady foi executada em duas etapas. A primeira etapa de 1994 a 1996 (em preto indicada na figura 2), conectava a Avenida da Integração à Avenida Xavantes e atravessava a ZPA 1. Essa etapa teve a localização da via desviada do projeto original para reduzir os impactos ambientais sobre o sistema dunar local. Tal proteção foi conquistada por meio de mobilização social, mas não houve, por parte do Poder Público, a transferência de dominialidade e a desapropriação dos novos lotes. (SEMURB, 2010).

A segunda etapa da Av. Omar O'Grady, inclui a fração aqui analisada (figura 2) e vai da Avenida Xavantes até a rua da consolação, onde se transforma em Av. Rio Jordão e alcança a BR101, dentro do município de Parnamirim/RN. Esta etapa, iniciada em 2007 e entregue em 2014, manteve a localização original do projeto do Conjunto Cidade Satélite e foi igualmente alvo de mobilizações sociais por cruzar o campo dunar e a ZPA 3 sobre o Rio Pitimbu.

Figura 2. Etapas de execução da Av. Omar O'Grady (prolongamento da Av. Prudente de Morais) e área lindeira em estudo.

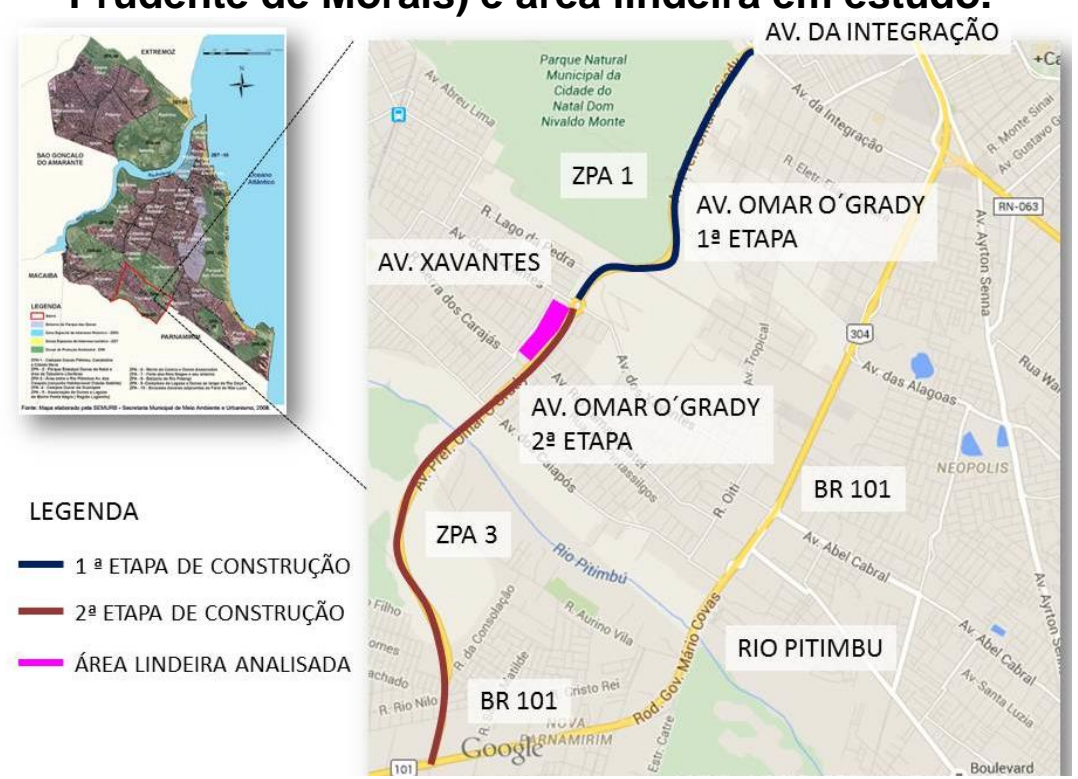

Fonte: Google Maps e SEMURB, 2008. Alterado pelos autores. 
Revista Nacional de

Gerenciamento de Cidades

Portanto, é possível identificar que originalmente, o projeto do Conjunto Habitacional Cidade Satélite definiu espaço para a localização das referidas Vias e suas respectivas faixas de domínio. Contudo, o projeto de prolongamento da Av. Prudente de Morais (Avenida Prefeito Omar O'Grady) não incorporou essas áreas como espaços públicos.

\section{FAIXA DE DOMÍNIO DA AVENIDA OMAR O'GRADY: ESTUDO DE DOMINIALIDADE}

Para compreender a dominialidade da área destinada à Avenida Prefeito Omar O'Grady (1978-2014 - final das obras) procedeu-se a um levantamento de dados em diversas fontes, resultando em um longo caminho de investigação. Ressalta-se que essa dificuldade associada à ausência de transparência sobre o domínio das terras públicas se colocam como um dos graves obstáculos para o monitoramento e controle social sobre os bens públicos.

Visando identificar os espaços públicos nas áreas lindeiras do sistema viário em estudo, buscou-se ter acesso aos dados na SEMURB - Secretaria Municipal de Meio Ambiente e Urbanismo - e no 6o Ofício de Notas, onde se obteve o mapa original do Conjunto de Cidade Satélite. Com esse documento, foi dado início ao estudo de campo, considerando os lotes do entorno da Av. Prefeito Omar O'Grady, localizados entre a Avenida Xavantes e Av. Rio Tamanduateí. Esse recorte espacial foi definido pela área em estudo estar inseridas entre duas zonas ambientais (ZPA 1 e ZPA 3) - Figura 2. Em seguida, procedeu-se à comparação entre projeto original e imagens aéreas atuais, confirmando a localização da via e dos espaços públicos definidos no Projeto original (Ver Figura 3). Destaca-se que as áreas de faixa de domínio da via e as áreas verdes estão contidas em uma mesma gleba, sem delimitações físicas. 
Revista Nacional de

Gerenciamento de Cidades

Figura 3. Sobreposição do mapa original (1978) da fração analisada com o mapa da fração fornecido pela SEMURB (2015)

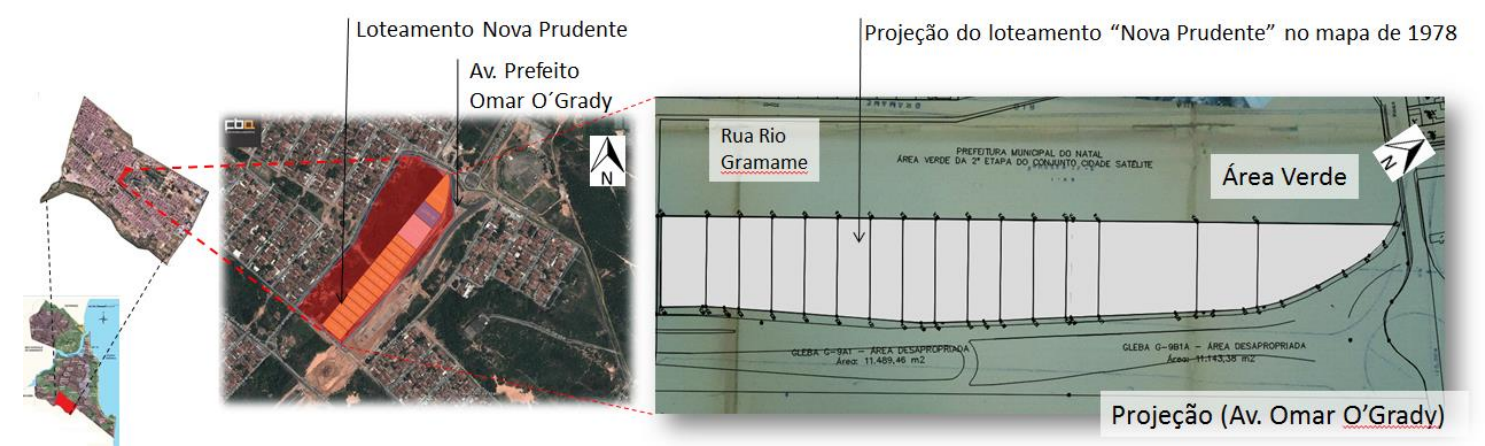

Fonte: $6^{\circ}$ Ofício de Notas, 1978 e SEMURB, 2015. Alterado pelos autores.

A partir do levantamento de dados em campo, identificou-se um anúncio de implantação do empreendimento imobiliário "Nova Prudente" - Figura 3, e a inserção de uma cerca, sobre a área que deveria configurar a faixa de domínio. Tal barreira física liberava como áreas públicas apenas às destinadas ao passeio, com aproximadamente 3 metros.

Apesar das obras do sistema viário não terem suprimido as áreas verdes definidas no projeto original, identifica-se que o licenciamento de tal empreendimento faz uma separação física entre a área verde e a via, sem considerar os espaços para a inclusão de vegetação, conforme estabelecido na Norma do DER de 1973 (BRASIL, 1973). Identifica-se assim, a ausência de conexão entre as ZPA 1 e ZPA 3 e destas com as áreas verdes internas ao bairro, resultando em um isolamento dos ecossistemas existentes e na redução da proteção ambiental.

Dessa maneira, a pesquisa evidencia que os 15 metros mínimos de área não edificável (Lei 6.766/79) não foram garantidos, em igual desatenção a legislação estadual (Lei 6204/91), tanto pelo licenciamento desse empreendimento, quanto pela não transferência de dominialidade da área pelo e para o ente público. Portanto, o empreendimento engessa a área lindeira da via para futuros melhoramentos, além de promover a privatização de espaços públicos coletivos. 
Revista Nacional de

Gerenciamento de Cidades

Para compreender as destinações dadas às referidas terras, procedeu-se ao levantamento de dados, por meio da matricula dos imóveis, no segundo cartório consultado, o $7^{\circ}$ Ofício de Notas - Natal/RN, conforme se relata a seguir.

\section{AVENIDA OMAR O'GRADY: HISTÓRICO DE DESTINAÇÕES DAS TERRAS LINDEIRAS}

Inicialmente, identificou-se no $7^{\circ}$ Ofício de Notas, por meio do Registro de Imóvel, no $2^{\circ} \mathrm{CRI}$, registro geral - livro n², Matrícula $\mathrm{n}^{\circ} 4.625$, que no ano de 1976 , toda a gleba que compõe o bairro Pitimbu, denominada "Peixe Boi", pertencia à empresa Nil Negócios de Imóveis Ltda. Através de contrato particular de compra e venda de ratificação de contrato de empréstimo e constituição de hipoteca, parte da gleba foi vendida, em 1977, ao Instituto de Orientação as Cooperativas Habitacionais do Rio Grande do Norte - INOCCOP/RN. Pelo contrato citado anteriormente, o INOCOOP/RN hipotecou a gleba ao Banco Nacional de Habitação (BNH), no mesmo ano (1977), e em meados de 1979, através da ratificação de contrato de empréstimo e de constituição de $2^{\circ}$ hipoteca, o proprietário responsável pelo INOCOOP/RN hipotecou a referida gleba ao BNH. Em 1980, houve um pedido pelo INOCOOP de desmembramento da gleba em três porções denominadas áreas "A", "B" e "C". Logo em seguida, de acordo com a $7^{\circ}$ Cláusula do Contrato de Compra e Venda de Retificação de Contrato de Empréstimo e Refinanciamento de Quitação de Hipoteca, firmado ainda no ano de 1980, entre o INOCOOP como devedor-vendedor ao BNH como credor, e a Cooperativa Habitacional Morro Branco como compradora, houve o cancelamento das duas hipotecas citadas anteriormente.

Porém, ainda no ano de 1980 houve uma desapropriação pelo DNER, em uma área inserida dentre as três glebas denominadas "A", "B" e "C", destinada ao prolongamento da Via de penetração, sem que haja no registro a delimitação e as coordenadas dessa região desapropriada. Em 2002, ocorreram diversos desmembramentos referentes às 13 glebas da grande área denominada "Peixe Boi". 
Revista Nacional de

Gerenciamento de Cidades

A gleba 9a corresponde a fração de terras em estudo. Em 2004, o Ministério Público disponibilizou qualquer ato jurídico a algumas das glebas citadas no Registro de Imóveis da $2^{\circ} \mathrm{CRI}$, contra a Cooperativa Habitacional Auto Financiável do RN CHAF, na fração que correspondia a área remanescente. Foi quando houve um requerimento pelo INOCOOP datado de 2011 solicitando o remembramento de uma das glebas anteriormente fragmentadas, na qual parte delas passou a formar uma única gleba. Em seguida, essa passaria a ser desmembrada em três glebas surgindo então, as três etapas do conjunto Cidade Satélite.

Em 2012, por motivos de pagamento de dívidas do INOCOOP, o Ministério Público colocou em Leilão a fração em estudo. Assim, por meio de ação civil pública houve a arrematação do imóvel que teve como compradora a empresa ECOCIL NOVA PRUDENTE INCORPORAÇÕES LTDA, que após a compra promoveu o desmembramento de tal gleba em 16 glebas menores, denominando-as de Loteamento Nova Prudente - o empreendimento (Figura 2 e 3).

Para tanto, a partir do Registro do Imóvel identificou-se que houve inoperância por parte do ente público no processo de desapropriação da faixa de domínio, fazendo com que a dominialidade da área fosse mantida constantemente com o setor privado, mesmo durante e após a execução da Via.

Com o licenciamento do empreendimento no local verificou-se a privatização de no mínimo $80 \%$ da área que seria destinada a faixa de domínio (dos $15 \mathrm{~m}$ da faixa de domínio, apenas $3 m-20 \%$ - foram destinados ao passeio público), resultando em uma perda considerável dos espaços coletivos. Essas evidências indicam que, a omissão do poder público em garantir as faixas de domínio, em favor dos processos especulativos incrementados com a implantação da via, comprometem significativamente a faixa de domínio, o que inviabiliza a implantação de qualquer ação futura de melhoramento do sistema de transporte e da segurança dos usuários. 


\section{CONSIDERAÇÕES SOBRE PROJETO VIÁRIO E SUPRESSÃO DA FAIXA DE DOMÍNIO: EXPANSÃO DO MERCADO, RESTRIÇÃO DAS FUNÇÕES PÚBLICAS}

Nesse artigo buscou-se demonstrar como as terras destinadas à faixa de domínio da Av. Omar O'Grady foram apropriadas, admitindo como hipótese que as terras lindeiras destinadas à faixa de domínio do prolongamento da Av. Prudente de Morais haviam sido privatizadas.

A pesquisa de dominialidade realizada e o cruzamento de dados cartográficos possibilitaram identificar que de fato, uma fração dos terrenos lindeiros a Av. Omar O'Grady, que deveriam ser destinados à faixa de domínio da Via, constituem propriedade privada já em 1978. Em que pese o processo legal de apropriação, o planejamento do prolongamento da Via atravessou 37 anos, sem que o Estado mobilizasse esforços para recuperar o estoque de terras necessário a implantação da faixa de domínio, o que significaria desapropriar e desmobilizar empreendimentos com alto valor de mercado, inclusive por efeitos da implantação da infraestrutura viária que já estava projetada desde os anos de 1980. Isso reforça a teoria de Villaça sobre o aumento do valor do solo urbano, com a implantação do sistema viário, que contribui para a "terra-localização", com acesso e localização do lote, através de recursos públicos. A supressão de parte da faixa de domínio resultou em um projeto viário destituído dos componentes de acessibilidade e urbanidade, restringindo-os a meros espaços de passagem.

Concluindo, ressalta-se que através da pesquisa realizada, verificou-se a dificuldade de acesso aos dados de dominialidade de terras, e principalmente aquelas de caráter público. Em que pese a facilidade em se obter informações nos Cartórios, o mesmo não se verificou com os demais dados, como base cartográfica, mapas antigos e atuais da área de estudo. Se de um lado a pesquisa evidenciou esses obstáculos, por outro lado coloca em discussão a relevância do desenvolvimento de estudos abrangendo a pesquisa de dominialidade, na perspectiva de contribuir para a transparência e a democratização das informações 


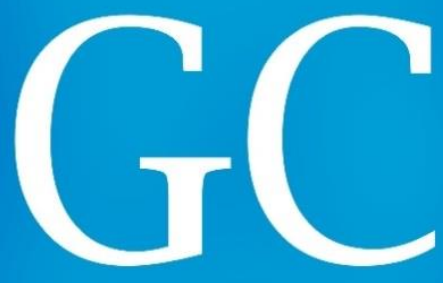

Revista Nacional de

OBSERVATÓRIO das metrópoles. Projeto Metropolização e Megaeventos: os impactos da Copa do Mundo 2014 e das Olimpíadas 2016. Natal, 2012. Disponível em:

<http://www.observatoriodasmetropoles.net/download/Relat_Natal2012.pdf>. Acesso em: 22 out. 2013. Relatório Parcial Natal

RIO GRANDE DO NORTE. Lei $\mathbf{n}{ }^{\circ} \mathbf{6 2 0 4}$ de 06 dezembro de 1991. Dispõe sobre licença prévia para edificações de imóveis ou cercas à margens de rodovias estaduais, e dá outras providências. Natal, 1991.

SEMURB. Memória minha comunidade: Cidade Satélite. Prefeitura do Natal. Secretaria Municipal de Meio Ambiente e Urbanismo. - Natal: SEMURB, 2010.200p.

VILLAÇA. Flávio. Espaço Intra-Urbano no Brasil. FAPESP: São Paulo, 2001. 